\title{
Investigation of influence of dipping structures on microtremor exploration from case study research
}

\author{
Kyosuke OKAMOTO ${ }^{1}$ and Seiji TSUNO ${ }^{1}$ \\ ${ }^{1}$ Center for Railway Earthquake Engineering Research, Railway Technical Research Institute
}

\begin{abstract}
Shallow S-wave velocity structures are estimated from dispersion curves of phase velocity, H/V spectral ratios, etc., using microtremor exploration technique. However the estimation is originally based on the assumption that layers of media are horizontally stratified. So, if layers of media incline or are discontinued, the estimated structures have errors to some extent. In this study, we tested a procedure of microtremor exploration for a dipping structure and examined the influence of the horizontal stratification assumption on the estimated structure. The followings are brief description of our procedure. At first, we determined S-wave velocity structures apart from the dipping area as references using the SPatial Auto Correlation (SPAC) method. The corresponding fundamental peak frequency of Rayleigh wave ellipticity was also obtained. Using the information from the reference structures, the dipping structure was determined by the $\mathrm{H} / \mathrm{V}$ spectral ratios which were obtained along the dipping structure under the assumption of the horizontal stratification. We found that the fundamental peak frequency shifts toward lower frequency smoothly as the structure becomes deeper. Using the determined structure, we numerically calculated influence range of the dip on the wave filed. As a result, it was revealed that the structure within one wavelength likely gives effect on the wave field and disturbs the H/V spectral ratios.
\end{abstract}

\section{Introduction}

S-wave velocity structures are estimated from microtremor by various methods, e.g., inversion analysis of dispersion curves, $\mathrm{H} / \mathrm{V}$ spectral ratios, joint inversion of both of them, etc. For the inversions, generally, theoretical dispersion curves and $\mathrm{H} / \mathrm{V}$ spectral ratios are obtained with the assumption that subsurface structures are horizontally stratified. So that, it is difficult to correctly image the irregular structures, such as dipping layers or discontinuities. Possible causes of this difficulty are that the irregular structures excite higher modes of surface waves and convert surface waves to body waves, making the observed wave field complicated (Uebayashi, 2003). The complicated wave field cannot be accountable by the horizontal stratification assumption. However precise estimation of the irregular structures is needed for disaster prevention. It is known that seismic waves are likely to be amplified at the irregular structures since the various seismic waves (surface waves, converted waves, etc.) interfere with each other. Seismic reflection surveys and boring surveys are useful to estimate the irregular structures, although sometimes they have difficulty in cost and space for the application.

In this study, we focus on $\mathrm{H} / \mathrm{V}$ spectral ratios, which are relatively easy to measure a wide range of areas with a small budget, to estimate a dipping structure. Uebayashi et al. (2008) pointed out that depth estimation of dipping structures by $\mathrm{H} / \mathrm{V}$ spectral ratios is more robust than other microtremor exploration, such like dispersion analysis. However, application of $\mathrm{H} / \mathrm{V}$ spectral ratios to dipping structures has some difficulties, e.g., produce of multiple peaks and indistinct peak, due to the structure-made complex wave filed as mentioned above. Moreover it is known that $\mathrm{H} / \mathrm{V}$ spectral ratios have tradeoff between $\mathrm{S}$-wave velocity and layer thickness (Scherbaum et al., 2003). So we estimated reference structures apart from a target dipping structure using the SPatial Auto Correlation (SPAC) method. Then, we estimated the dipping structure from spatially dense observations of $\mathrm{H} / \mathrm{V}$ spectral ratios along the dip, using the reference structures and the corresponding fundamental peak frequency of Rayleigh wave ellipticity. The influence of the dip on the H/V spectral ratios of the estimated model was examined using a numerical calculation since we employed the assumption of horizontal stratification.

\section{MICROTREMOR OBSERVATION}

Microtremor observations (three array surveys for the SPAC and eleven single station measurements for $\mathrm{H} / \mathrm{V}$ spectral ratio) were conducted on Nov. 20 and 21, 2014 at an anonymous site in Japan (Figure 1). JEP-6A3 and JEP-6A1U sensors (Mitsutoyo) and LS-8800 logger (HAKUSAN) were used for the array surveys. 

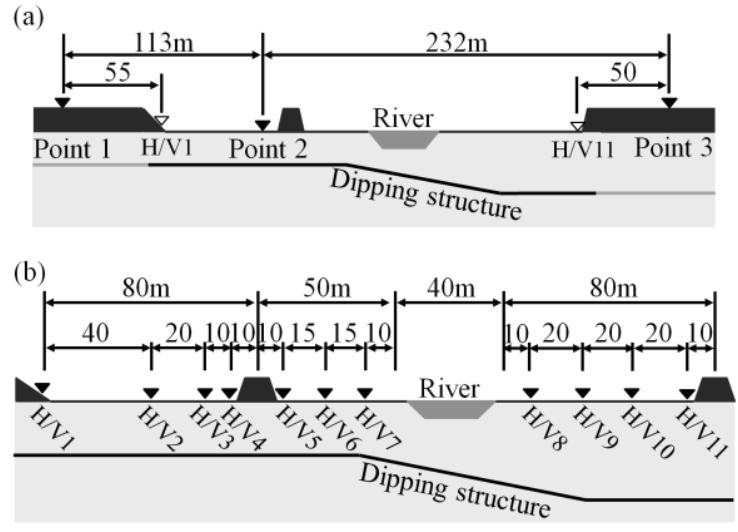

Figure 1. Geometry of the observations. (a) Array observations were conducted at Point 1, 2 and 3 apart from the dipping structure. (b) $\mathrm{H} / \mathrm{V}$ spectral ratios were measured along the dipping structures at 11 observation points named H/V1 - 11 .

CR4.5-2S sensor (ANET) and MESSE logger (ANET) were used for the single station observations. A dipping structure in the shallow subsurface had been indicated by boring surveys at the site for the construction of a railway bridge. The fall of the dip reaches several $10 \mathrm{~m}$ while the horizontal length is several $100 \mathrm{~m}$. Around the site, no active faults have been found. Apart from the dip, triangular and L-shaped arrays were conducted at Point 1, 2 and 3 shown in Figure 1a. Dispersion curves were obtained by the SPAC method at each Point and five layered structures were estimated (Figure 2) using a Genetic Algorithm (GA, Yamanaka and Ishida, 1995). In comparison with Point 1 and 2, deeper $\mathrm{S}$-wave velocity structure is estimated at Point 3. It suggests the dipping structure between Point 2 and 3 .

Spatially dense observations of $\mathrm{H} / \mathrm{V}$ spectral ratios along the anticipated dipping structure (H/V1 - 11 points in Figure $1 \mathrm{~b}$ ) were conducted to estimate it precisely. Five layered structures were estimated using the GA at each $\mathrm{H} / \mathrm{V}$ observation points. S-wave velocities and thickness of the layers were searched according to the following procedure. For the case of a $\mathrm{H} / \mathrm{V}$ observation point between Point 1 and 2, the thickness (and S-wave velocity) of the first layer is searched between $-10 \%$ of the thinner thickness (the slower velocity) and $+10 \%$ of the thicker thickness (the faster velocity) of Point 1 and 2. The same procedure was applied for the other $\mathrm{H} / \mathrm{V}$ observation points and the layers. The observed $\mathrm{H} / \mathrm{V}$ spectral ratios were smoothed with the Parzen window of $0.2 \mathrm{~Hz}$ length. The analyzed frequency range of the $\mathrm{H} / \mathrm{V}$ spectral ratios is important factor for the result (e.g., Hobiger et al., 2013). In this study, we used the frequency range between the fundamental Rayleigh wave peaks of

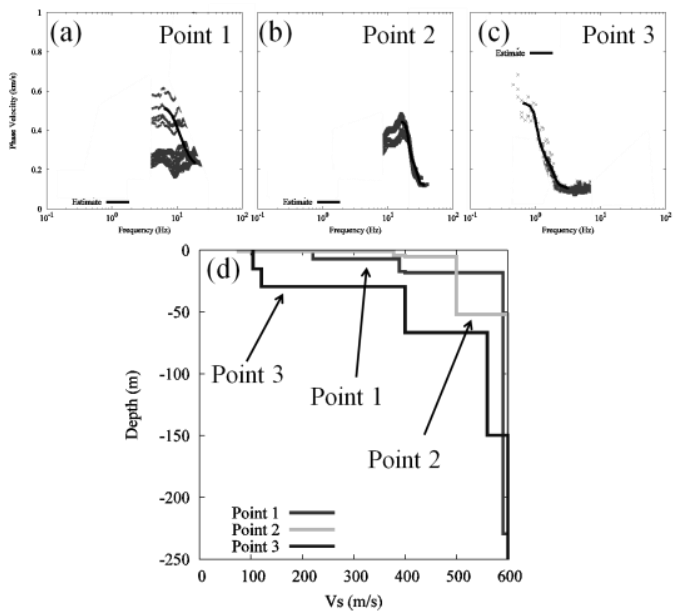

Figure 2. Observed phase velocities (dots) for (a) Point 1, (b) Point 2 and (c) Point 3. The solid lines are theoretical dispersion curves. (d) Estimated S-wave velocity structure.

$\mathrm{H} / \mathrm{V}$ spectral ratios of Point 1 and 2 (or Point 2 and 3). The observed $\mathrm{H} / \mathrm{V}$ spectral ratios and the theoretical fundamental peaks of the reference models (result of the SPAC method) are shown in Figure 3.

By the procedure explained above, S-wave velocity structures were estimated at each $\mathrm{H} / \mathrm{V}$ observation point. The observed $\mathrm{H} / \mathrm{V}$ spectral ratios and the theoretical $\mathrm{H} / \mathrm{V}$ spectral ratios (the fundamental mode of Rayleigh waves) of the estimated models are shown in Figure 4. At H/V1 7, which are supposed to locate on the shallower structure, the peak frequencies are relatively high.

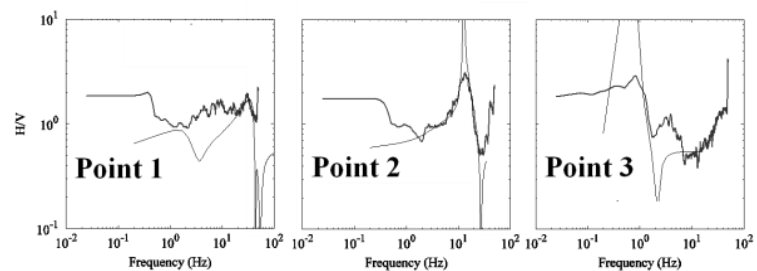

Figure 3. Observed $\mathrm{H} / \mathrm{V}$ spectral ratios (bold line) and theoretical one calculated from the estimated models (thin line).

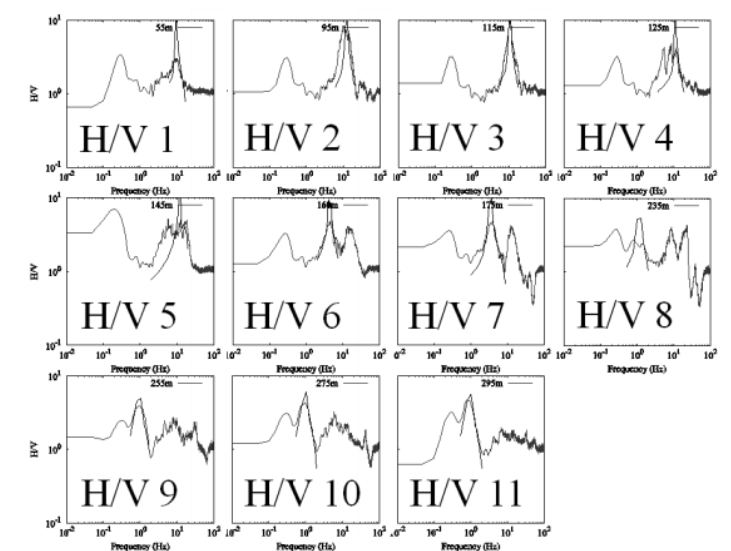

Figure 4. Observed $\mathrm{H} / \mathrm{V}$ spectral ratios (bold line) and theoretical one calculated from the estimated models (thin line). 


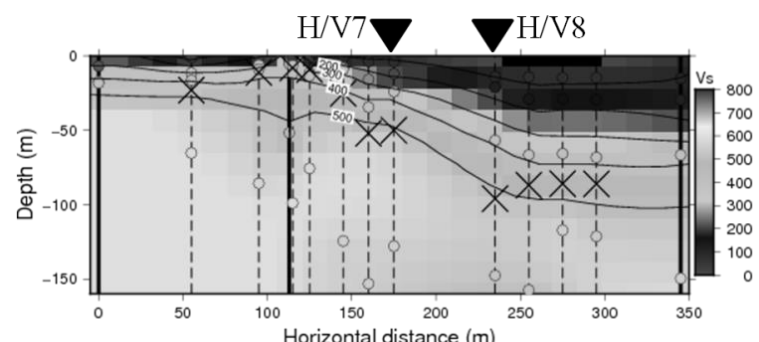

Figure 5

Estimated model from the observations. The locations of the array observations are shown by the solid lines and $\mathrm{H} / \mathrm{V}$ observation points the dashed lines. $(x)$ indicates the depth of node of Rayleigh wave.

On the other hand, the peak frequencies are relatively low at $\mathrm{H} / \mathrm{V} 8-11$, suggesting the relatively deeper structure. The model integrated the result of the dispersion analysis and the H/V spectral ratios is shown in Figure 5. The dipping structure is estimated between $\mathrm{H} / \mathrm{V} 7$ and $\mathrm{H} / \mathrm{V} 8$, which agrees with the result of the boring surveys. It is worth noting that the interval between those observation points is relatively long since the observation is not possible there due to the river. However the frequency ranges which the GA chose for searching the fundamental mode of Rayleigh wave ellipticity jumped at H/V8 (see Figure 4). So we would like to precisely examine the structure-made shift of the fundamental mode between H/V7 and H/V8 and influence of the dipping structure on the observed $\mathrm{H} / \mathrm{V}$ spectral ratios.

\section{NUMERICAL CALCULATION}

We employed a 2-D finite difference method with the rotated staggered grid (Saenger et al., 2000), which can accurately calculate wave propagations in the media having high impedance contrast, such like the air and the ground. The estimated model shown in Figure 5 was divided into $448 \times 243$ grids and about 42 seconds long seismograms were synthesized. White noises were put at the 65 grids at random between the surface and the 20m depth. The PML condition (Drossaert and Ginnopoulos, 2007) was introduced to the lateral and bottom boundaries. Receivers were put

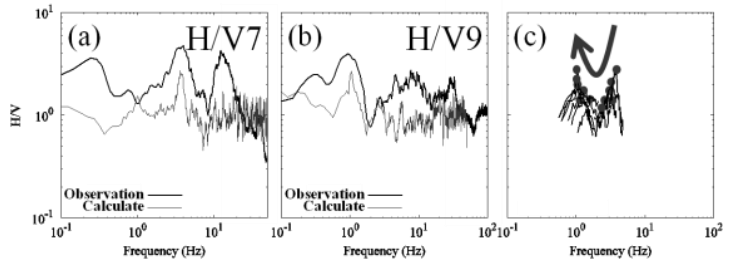

Figure 6 Observed (black line) and calculated (gray line) $\mathrm{H} / \mathrm{V}$ spectral ratios at (a) the $\mathrm{H} / \mathrm{V} 7$ and (b) the H/V9. (c) Extraction of the peaks of the calculated $\mathrm{H} / \mathrm{V}$ spectral ratios between H/V7 and H/V9. • shows the peak position. on the surface with $4 \mathrm{~m}$ intervals.

Figures $6 \mathrm{a}$ and $\mathrm{b}$ are the numerically calculated $\mathrm{H} / \mathrm{V}$ spectral ratios and the observed one at $\mathrm{H} / \mathrm{V} 7$ and $\mathrm{H} / \mathrm{V} 9$. Note that the result of H/V9 is shown instead of that of $\mathrm{H} / \mathrm{V} 8$ since the observed peak at H/V8 is obscure. The fundamental peaks of the numerically calculated $\mathrm{H} / \mathrm{V}$ spectral ratios are coincide with those of the observed one at both H/V7 and H/V9. It suggests that the estimated model is appropriate. Figure $6 \mathrm{c}$ shows the transition of the fundamental peak of the calculated $\mathrm{H} / \mathrm{V}$ spectral ratios between $\mathrm{H} / \mathrm{V} 7$ and H/V9. The transition is shown with $8 \mathrm{~m}$ intervals. Toward to H/V9 from $\mathrm{H} / \mathrm{V} 7$, the fundamental peak shifts in the direction of the arrow (Figure 6c). Only from the observation result (Figure 4), continuity of the peak shift between H/V7 and H/V9 is uncertain. However the numerical calculation revealed that the peak shifts continuously. Also it revealed that the peak at $\mathrm{H} / \mathrm{V} 8$ is obscure in comparison with that of $\mathrm{H} / \mathrm{V} 9$ or $\mathrm{H} / \mathrm{V} 10$ because the peak is on the way to shift completely. From the numerical calculation, it was found that dipping structures are detectable by tracking a shift of the fundamental peak of $\mathrm{H} / \mathrm{V}$ spectral ratios.

\section{EFFECT OF DIPPING ON WAVE FILED}

The inversion analysis of the observed $\mathrm{H} / \mathrm{V}$ spectral ratios is based on the assumption of horizontal stratification, while the real structure is dipped. The dip makes conversion waves, excites higher modes of surface waves and causes various phenomena, which make the wave filed complicated and the $\mathrm{H} / \mathrm{V}$ spectral ratio different from the one obtained from the horizontally stratified structure. For example the fundamental peak becomes obscure, which is generally the clearest peak in horizontally stratified structures. Multiple peaks are also produced due to higher modes of surface waves and converted body waves. Those phenomena are recognized in the result of H/V7 and H/V8 (see Figure 4). The H/V spectral ratio at $\mathrm{H} / \mathrm{V} 7$ shows the peak of the first mode of Rayleigh wave ellipticity around $12 \mathrm{~Hz}$. The fundamental peak becomes blunt at $\mathrm{H} / \mathrm{V} 8$. We examined the cause of the blunt fundamental peak. For the purpose, we employed an adjoint method (e.g., Tromp et al., 2005). We calculated sensitivity kernels between the wave filed of the dipping structure and structure-made reflections. The reflected waves are extracted using $f-k$ filtering method (Figure 7).

Figure 8 shows the sensitivity kernels of $1 \mathrm{~Hz}$. The most sensitive area is several $10 \mathrm{~m}$ under H/V8. Moreover the top of the dipping structure within 
(a)

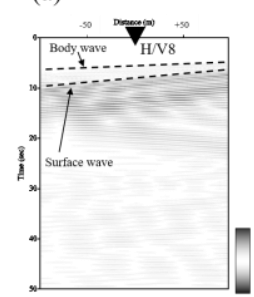

(b)

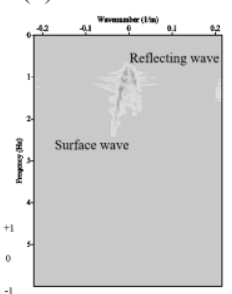

(c)

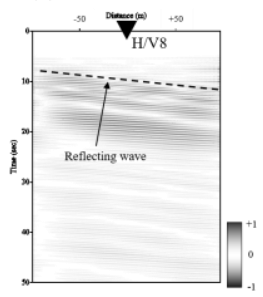

Figure 7 (a) Calculated wave field around $\mathrm{H} / \mathrm{V} 8$ and (b) its image in the $\mathrm{f}-\mathrm{k}$ domain. (c) The reflecting waves extracted using the f-k filter. In (a) and (c), the amplitude is normalized by the maximum amplitude.

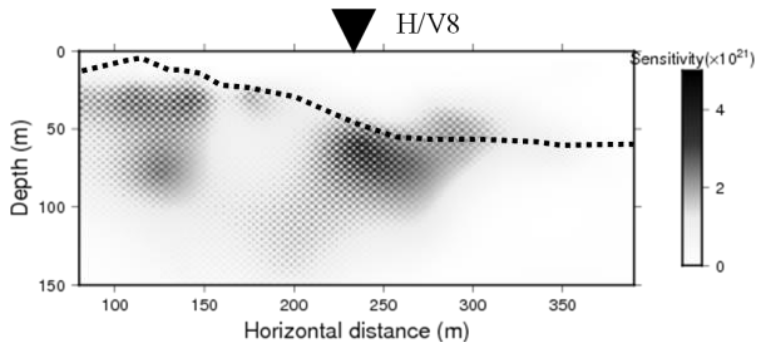

Figure 8 Spatial distribution of sensitivity kernel of shear wave.

one wavelength (Vs near the surface is about $100 \mathrm{~m} / \mathrm{s}$, so that the corresponding wavelength is about $100 \mathrm{~m}$ ) also has sensitivity. It means that the reflections of the initial surface wave likely occur there, and it makes $\mathrm{H} / \mathrm{V}$ spectral ratio complicated. Here, note that only the peak of the $\mathrm{H} / \mathrm{V}$ spectral ratios around $1 \mathrm{~Hz}$ was analyzed. Conversions from other frequency to $1 \mathrm{~Hz}$ band were not considered. Not only layer structures but also the comparable sized scattereres may give apparent velocity change (Okamoto et al., 2013), so that, more detailed surveys are needed to understand the complicated wave field.

\section{SAMARRY}

In this study, we applied spatially dense observations of $\mathrm{H} / \mathrm{V}$ spectral ratios to estimate a dipping structure. At first, a couple of reference structures were determined using the SPAC method apart from the dipping structure. From the reference structures, the corresponding fundamental peaks of Rayleigh wave ellipticity were obtained. Then, inversion analysis of the observed $\mathrm{H} / \mathrm{V}$ spectral ratios was conducted for the fundamental peak frequency of the reference models and the dipping structure was successfully estimated, although the dip made the wave filed complex. According to the adjoint method, the structure within one wavelength likely gave the effect on the wave filed.

\section{REFERENCES}

1) Drossaert, F. H., and Giannopoulos, A., 2007, Complex frequency shifted convolution PML for FDTD modeling of elastic waves, Wave Motion, 44, 593-604.

2) Hobiger, M., Cornou, C., Wathelet, M., Giulio, G. D., Knapmeyer-Endrun, B., Renaler, F., Bard, P. Y., Savvaidis, A., Hailemikael, S., Bihan, N. L., Onhrnberger, M., and Theodoulidis, N., 2013, Ground structure imaging by inversions of Rayleigh wave ellipticity: sensitivity analysis and application to European strong-motion sites, Geophys. J. Int., 192, 207-229.

3) Okamoto, K., Mikada, H., Goto, T-N., and Takekawa, J., 2013, Numerical analysis of the relationship between time-variant coda-Q and the variation in crustal stress, Geohys. J. Int., 195, 575-581.

4) Saenger E. H., Gold, N., Shapiro, S. A., 2000, Modeling the propagation of elastic waves using a modified finite-difference grid, Wave Motion, 31, 77-92.

5) Scherbaum, F., Hinzen, F. K., and Ohrnberger, M., 2003, Determination of shallow shear wave velocity profiles in the Cologne, Germany area using ambient vibrations, Geophys. J. Int, 152, 597-612.

6) Tromp, J., Tape, C., and Liu, Q., 2005, Seismic tomography, adjoint methods, time reversal and banana-doughnut kernels, Geophys. J. Int., 160, 195-216.

7) Uebayashi, H., 2003, Extrapolation of irregular subsurface structures using the Horizontal-to-Vertical spectral ratio of long-period microtremors, 2003, Bull. Seism. Soc. Am., 93, 570-582.

8) Uebayashi, H., Kawabe, H., Kamae, K., and Horike, M., 2008, Behavior of microtremor $\mathrm{H} / \mathrm{V}$ spectrum and phase velocity on the basin peripheral and inversion for determining basin structure, The 14th World Conference on Earthquake Engineering, Expanded Abstract.

9) Yamanaka, H., and Ishida, H., 1996, Apprication of genetic algorithms to an inversion of surface-wave dispersion data, Bull. Seism. Soc. Am., 86, 436-444 